\title{
Reescrevendo Jesus: o Evangelho segundo Norman Mailer e Gore Vidal
}

Delzi Alves Laranjeira

Resumo

Em O Evangelho segundo o Filho, Norman Mailer reescreve os Evangelhos sob o ponto de vista de Jesus. Ao vivo do Calvário, de Gore Vidal, apresenta uma versão blasfema e subversiva da vida de Jesus nas entrelinhas do texto dos Atos dos Apóstolos. Ambos os romances contribuem para um questionamento de premissas cristãs.

Palavras-chave: Reescrita. Evangelhos. Revisão. Subversão.

Retomar Jesus como personagem em contraponto ao texto bíblico, uma narrativa com uma carga cultural e religiosa de quase vinte séculos, é, sem dúvida, "um desafio especial", como enfatizado por Leyla Perrone-Moisés (1999, p. 240). Norman Mailer, em $O$ Evangelho segundo o Filho, e Gore Vidal, em Ao vivo do Calvário, enfrentaram o desafio de escrever um Evangelho literário, elaborando representações alternativas de Jesus. Mailer baseou-se nos Evangelhos canônicos e apócrifos, enquanto Vidal construiu sua versão reescrevendo os Atos dos Apóstolos. A figura de Jesus na literatura moderna freqüentemente não reflete o Cristo das Escrituras. Como observou Blehl (1967, p. 111), ${ }^{1}$ os escritores "são livres para fazer o que quiserem da figura de Cristo, mas as crenças do autor determinarão a significância de seu simbolismo e imagens". A análise do personagem Jesus apresentado em cada romance permitirá inferir quão diferente (ou semelhante) é esse personagem em relação à tradição religiosa e que tipo de contribuição a ficção proporciona ao adicionar mais uma camada à já extensa maneira de conceber Jesus não mais como noumenon, mas phenomenon.

A perspectiva literária utilizada para focalizar as recriações ficcionais de Vidal e Mailer enfatiza a adoção de parâmetros como reescrita e intertextualidade, os quais constituem as bases das relações que os romances podem estabelecer com o texto bíblico, relação que se pretende de mão-dupla, em que ambos os sistemas iluminam aspectos que possibilitam novas maneiras de apreendê-los. Nesse contexto, reescrita é definida como "uma forma intertextual que enfatiza fortes vínculos com obras cronologicamente anteriores, cujo traço é discernível no texto e é marcado pelo autor como uma presença "'intencional' em vez de um eco esquivo e indistinto" (MORARU, 2001 , p. 19). O texto posterior é nomeado reescrita (rewrite) e o texto prévio, reescrito (rewritten). A renarração do reescrito é essencial para caracterizar o tipo de reescrita a que Moraru se refere e, portanto, a presença de uns "poucos intertextos 
insuficientemente desenvolvidos" ou que não se configuram como centrais para a obra não permite classificá-la como reescrita. É fundamental que se possa reconstruir, na reescrita, a estrutura análoga do texto anterior, primeiro "como enredo ou segmento de enredo, personagens, motivos e então, mais amplamente, como doutrina estética, estilo ou ideologia" (MORARU, 2001, p. 20). É sob essa ótica que se pretende entender os romances de Mailer e Vidal como reescritas, uma vez que é claramente possível identificar analogias de enredo, personagens, estilo e ideologia - nesse caso, uma "contra-ideologia", já que os romances revisam a versão oficial.

Moraru caracteriza essa forma de reescrita como sendo simultaneamente intensiva e extensiva. A intensidade é definida como a operação textual (a renarração em si), e a extensão diz respeito a seu caráter crítico, em termos políticos e ideológicos. A intensidade varia com o grau de autoconsciência no processo de reescrita e, para Moraru (2001, p. 25), quanto mais esse processo é "enfatizado, exibido, tematizado e teorizado como um princípio construtor central" da obra, mais intensiva é a reescrita. Já a extensão avalia quão "ostensiva e programaticamente [...] [a reescrita] desloca e repõe mais do que intertextos literários e modos de textualização" (MORARU, 2001, p. 26), ou seja, como as "tendências críticas e revisionistas" da reescrita se manifestam e são percebidas.

Ao reescrever a história de Jesus em O Evangelho segundo o Filho, Mailer desloca o foco para a humanidade de Jesus, uma vez que, na sua opinião, os evangelistas colocam pouca ênfase nesse aspecto. Para mostrar esse Jesus humano, Mailer recorre à narrativa em primeira pessoa, pois essa estratégia permite acesso à mente do personagem, expondo suas opiniões, medos e desejos; os sentimentos, enfim, que traduzem sua humanidade. Ademais, acrescenta Mailer, "não há sentido em reescrever [a história de Jesus] a não ser que se possa penetrar na mente [dele], ao menos do meu ponto de vista. [...] Eu não pretendo entender o deus, mas o homem que passou por toda aquela experiência" (CARLIN, 1997). Assim, o romance reforça o que Jesus, como homem, sente enquanto vive "toda aquela experiência", do nascimento à crucificação. Uma vez que os fatos narrados no romance são praticamente os mesmos dos Evangelhos, o relato dos sentimentos de Jesus se constituirá como um importante diferencial e trará à luz o Jesus homem obscurecido pelo deus.

No romance, o conflito de ser homem e deus parece ter estado sempre com Jesus. O intervalo entre os doze e os trinta anos de sua vida manteve esse conflito latente. As habilidades de carpinteiro "faziam com que [Jesus se] sentisse em paz", mas ele próprio observa que "rara é a calma que perdura longo tempo, mantendo-se livre de perturbações". Essa turbulência de emoções o leva a dizer que se sentia "cheio de avidez, a ponto de [...] sufocar. [...] Enfim, achava-me pronto. Como - não sabia. Havia um homem encarcerado dentro de mim". ${ }^{2}$ O batismo, a tentação no deserto, os milagres, o ministério, a morte na cruz farão emergir esse outro que é divino, mas ele estará indelevelmente vinculado a esse Jesus humano. O Evangelho segundo o Filho coloca em evidência a complexidade desse amálgama, revelando-a nas reações e sentimentos do homem Jesus.

Em relação à sua identidade, perplexidade, dúvida e aceitação são sentimentos que se revezam, suscitando um tumulto de emoções. Nos Evangelhos sinópticos, Jesus muitas vezes age com reserva quando o assunto gira em torno de quem e o que ele é. Já no Evangelho de João ele permanece, do começo ao fim, convicto do fato de ser o Messias (STRAUSS, 1994, p. 284). No romance, Mailer parece ter optado pela exposição mais fluida dos sinópticos acerca da identidade de Jesus. A diferença que insere é o relato de como ele assimilou o papel que the fora supostamente destinado. 
No seu relato, Jesus expõe suas emoções diante dos fatos, preocupação que os evangelistas não tiveram, porque ainda que o personagem do romance, algumas vezes, pedisse aos apóstolos e às pessoas que curava que não falassem a respeito dele e de quem era, e ainda que se mantivesse reticente sobre isso, a convicção de seu messianismo existia desde o início. Nos Evangelhos, os motivos pelos quais Jesus não anunciava abertamente e de imediato sua condição de Messias seriam estratégicos, e não devido a incertezas pessoais. No entanto, essa "vacilação discernível" (STRAUSS, 1994, p. 284) quanto à identidade de Jesus nos sinópticos abre uma lacuna na interpretação do texto bíblico, e é dentro deste espaço que Mailer procura evidenciar a humanidade de Jesus.

Uma característica marcante do Jesus de Mailer é sua aguda percepção olfativa. Do aroma da madeira com que trabalha em seus dias de carpinteiro ao odor dos pés dos apóstolos que ele lava, após a ceia final, o cheiro das coisas possui um papel significativo no relato de Jesus. O hálito de João Batista, quando o batiza, é "impregnado de tudo o que exala um homem depauperado" e sua pele dissemina "o mesmo odor do Jordão" (ESF, p. 35). O corpo do diabo exala "um odor parecido ao que vive entre as nádegas" e, ao ser tentado por ele, o cheiro da comida que o diabo lhe oferece excita seu apetite (ESF, p. 42). Ao se referir aos escribas do templo, ressalta que "o odor da sua santidade sabia a moluscos mortos" (ESF, p. 71) e, quando ressuscita Lázaro, sente-se preparado "para sentir o odor da morte" (ESF, p. 125). Quando Jesus é ungido com óleo de nardo pela mulher identificada como Maria, a casa onde se encontra fica "completamente tomada pelo perfume", que "fora um bálsamo para a solidão que rugia no [...] [seu] ventre" (ESF, p. 166). O perfume traz à memória versos do Cântico dos Cânticos e traduz "um instante de felicidade" (ESF, p. 166). Os pés dos apóstolos, uns limpos, outros cheirando mal, evidenciam a diversidade entre eles: "alguns tinham as pernas rijas, mas outros logo estariam prontos para fugir" (ESF, p. 172). Entre a gama de emoções e sentimentos que Jesus descreve, destacar a atuação de um sentido - o olfato - mostra-se uma maneira singular de apreender as coisas. Aplicada a Jesus, na sua biografia, ressalta ainda mais sua humanidade, em um contexto puramente biológico. Os sentidos não deixam de ser importantes para Jesus. Afinal, ele faz os cegos verem, os mudos falarem, os surdos ouvirem, os leprosos sentirem. Os cheiros do mundo, ele os capta e os traduz.

Nos Evangelhos, os sofrimentos físicos de Jesus assumem uma dimensão maior depois de sua prisão, quando é maltratado pelos sacerdotes do templo e pela guarda romana. Antes da prisão temos, nos Evangelhos sinópticos, a cena da angústia suprema de Jesus no Getsêmani, onde chega a porejar sangue, na versão de Lucas. Mas em nenhum desses relatos o sofrimento de Jesus é descrito em detalhes. Ele é açoitado, cuspido, crucificado, mas não sabemos como se sentiu. Em $O$ Evangelho segundo o Filho, Jesus fala com freqüência de suas dores, suas febres, sua insônia. Esta última ou o atormentava, ou o deixava exaurido. A consciência da dor acentua-se na crucificação, quando Jesus diz que sua "alma iluminou-se de dor" e "[q]uando levantaram a cruz do chão foi como se [ele] subisse mais alto e com mais dor ainda. Um sofrimento tão vasto quanto os mares" (ESF, p. 195), que aniquila seu corpo e, em alguns momentos, desestabiliza sua fé.

O Jesus homem termina sua jornada imerso em dor, mas também em esperança. Reconcilia-se, enfim, com sua própria divindade. É o que se pode concluir da versão de Jesus proposta por Mailer, em $O$ Evangelho segundo o Filho: a exposição de sua humanidade não submerge sua consciência de ser também divino. Mailer, apesar da ênfase no Jesus homem, não descartou o Jesus divino, principalmente porque opta por 
trilhar um caminho muito próximo dos Evangelhos, nos quais o fiel da balança pende mais para o aspecto divino. Miles (2002, p. 307) comenta que, em termos literários, Jesus "deve ser sempre, ao mesmo tempo, divino e humano". Portanto, não surpreende que o Jesus do romance, quase dois mil anos após os acontecimentos e agora somente como Jesus divino, termine sua narrativa confessando-se como um ser triste, mas que procura extrair da sua tristeza "uma compaixão imutável e vontade imbatível de viver e regozijar[-se]" (ESF, p. 204). Um pensamento, sem dúvida, demasiado humano.

Em Ao vivo do Calvário, de Gore Vidal, embora Jesus não seja o personagem principal, sua figura compõe, com Timóteo e Santo (o apóstolo Paulo), a "trindade vidaliana" do romance. Jesus é a causa da existência do cristianismo, Santo é o seu administrador e disseminador, e Timóteo é o escolhido para contar toda a história. Nos três casos, Vidal subverte profundamente as implicações religiosas relacionadas a essas figuras, e a de Jesus, ao se basear na versão apresentada pelo narrador Timóteo, situa-se em algum lugar bem distante de onde a colocou o imaginário cristão. Esse "anticristo" que Vidal constrói em seu "antievangelho" não é simplesmente uma oposição binária ao Jesus canonizado, mas um vetor que Vidal usa para articular uma crítica corrosiva dos dogmas cristãos e minar o contexto que os produziu.

Segundo Price (2000, p. 15), o Jesus Cristo do Novo Testamento "é uma figura composta" e apresenta muitas facetas: "exorcista, curandeiro, rei, profeta, sábio, rabino, semideus, e por aí vai". O Jesus de Vidal também se caracteriza pela multiplicidade, desdobrando-se ao longo da narrativa: há o Jesus "reinterpretado" de Santo, Judas crucificado em seu lugar, o Jesus sionista revolucionário, que se desdobra em Marvin, um "detetive analista de computadores", e o Pirata, um hacker que está destruindo os registros da história cristã.

O Jesus sionista, que é o "real" e "histórico" na versão de Vidal, é o mais subversivo dos desdobramentos de sua figura no romance, pois a sua participação na história judaica no primeiro século em nada se coaduna com a versão dos Evangelistas e Paulo; na verdade, ela a rasura em todos os sentidos, a se basear no relato de Timóteo. A questão envolvendo Jesus, os judeus e os romanos, por exemplo, é colocada sob uma perspectiva econômica e não teológica. As ações de Jesus visavam ao controle do Templo e às rédeas da política econômico-monetária, e não à transformação da visão de mundo vigente através de um novo discurso religioso. Não há curas, não há milagres, não há Deus, não há parábolas - no máximo, os sermões de "rabino reformista", os quais, ao que tudo indica, significavam um discurso conclamando mudanças político-econômicas para o povo judaico. Como afirma Timóteo, "[n]a vida real Jesus foi de fato o rei judeu, que ameaçara o domínio romano ao mesmo tempo que o do rabinado do Templo". ${ }^{3}$ Contudo, esse Jesus não é o que passará para a história, simplesmente porque a sua "verdadeira história" não será conhecida, mas devidamente manipulada, como revela Timóteo com uma dose de candura e sarcasmo: "[n]aturalmente não ensinamos a verdadeira causa da crucificação mas somente a reportagem de capa" (AVDC, p. 114). O que se deduz que seja a "reportagem de capa" é o Jesus inventado por Santo, cuja morte na cruz foi para redimir a humanidade de seus pecados e cuja ressurreição é a razão suprema para a fé em sua doutrina. ${ }^{4}$

Toda a interpretação de Santo, contudo, foi baseada na crucificação de Judas e não do Jesus real, o que a torna duplamente "falsa": a história fictícia de um homem que não era Jesus. A crucificação no romance é abordada de uma forma tão profana que o conceito de carnavalização é o que vem à mente para explicar esta 
caracterização tão insólita. A rigor, duas crucificações são consideradas: a de Judas e a do Jesus "real". A mimetização de Judas em Jesus é um dos pontos altos da carnavalização das personagens cristãs proposta por Vidal em Ao vivo do Calvário: Jesus entrega para ser crucificado o discípulo que, na versão oficial, é aquele que o trai. Enquanto Judas desmaia aos pés dos soldados romanos, Jesus abandona o Getsêmani e, entrando na máquina do tempo, foge para o final do século 20 . Na crucificação de Judas, temos: a inversão perversa quando o discípulo é crucificado em lugar do mestre, a transgressão de barreiras espaciais e temporais, e a degradação do sagrado, quando os discípulos e parentes de Jesus são coniventes com a farsa da crucificação.

Denunciado por Timóteo - que agora faz o papel de Judas -, Jesus é capturado pelos romanos e cumpre seu destino de morrer na cruz. Ao ser questionado sobre sua identidade, responde: "Eu sou o que sou", ecoando o Deus de Moisés no episódio da sarça ardente (AVDC, p. 210). Na perspectiva do romance, porém, essa declaração permite interpretações que vão além da alusão ao texto do Êxodo. Jesus é o que é, e isso significa ser o que os interesses do momento estipulam. Com a sua história alterada pelos evangelistas, por Paulo, pela Igreja, pela mídia, por Timóteo, Jesus é o que é feito dele, "hoje e sempre". Tanto que a crucificação do Jesus "real" não levou aos resultados almejados por Santo e Timóteo, ou seja, não restaurou o cristianismo paulino, mas sim, instituiu um cristianismo niponizado. Sua história é moldável como matéria plástica, ou reescrevível como um palimpsesto, como confirmam os Evangelhos adulterados das duas últimas páginas do romance. No Evangelho segundo Gore Vidal, Jesus é "feito à nossa vontade". Nietzsche, de uma certa forma, liberou Jesus da responsabilidade de ter criado o cristianismo, a religião da decadência, na sua opinião. Contudo, não perdoou Paulo por converter o Evangelho "na promessa irrealizável mais digna de desprezo, a doutrina insolente da imortalidade pessoal", a qual ele "teve o descaro de apresentar como uma recompensa!..." (NIETZSCHE, 2002, p. 77). Vidal diferencia-se do filósofo alemão por ter escolhido não poupar nenhum dos dois em sua proposta de problematizar e provocar o que está "institucionalizado e dogmatizado" no cristianismo (SOUSA, 2002, p. 29).

Os romances de Mailer e Vidal são representativos de uma prática largamente disseminada na narrativa contemporânea pós-moderna: a reescrita de histórias culturalmente centrais e dominantes. Como reescritas de histórias bíblicas familiares, O Evangelho segundo o Filho e Ao vivo do Calvário promovem uma investigação das potencialidades e conseqüências da reformulação de textos prévios, especialmente no que diz respeito à forma como essas narrativas mestras operam para conferir uma noção de realidade e verdade para seus leitores. A análise dos romances permite situálos dentro dessa perspectiva, uma vez que suas relações com seu reescrito, notadamente em Vidal, são marcadas pelo caráter extensivo, pois exibem um impulso revisionista e questionador, ao subverter a narrativa bíblica como grand récit, minando uma visão institucionalizada do texto bíblico como ratificador de dogmas doutrinários e verdades - ou "a verdade".

Tanto Mailer quanto Vidal reconhecem o cristianismo como uma das maiores forças da cultura ocidental, e propõem, à sua maneira, uma interpretação alternativa à proposta pela visão monolítica das instituições religiosas cristãs. Para tanto, utilizam a mesma ferramenta que garantiu essa posição central ao cristianismo: sua narrativa poderosa, seus enredos e personagens recontados, endossados e refutados ad infinitum. O posicionamento desafiador dessas reescritas mina o amálgama que sustenta a estrutura desses mitos, sem, contudo, significar que eles 
perderam sentido ou se tornaram inúteis. Sua apropriação literária só faz reafirmar a constante reciclagem a que estão sujeitos, sempre passíveis de novas abordagens e interpretações.

Notas

${ }_{1}$ As traduções de todos os textos em língua estrangeira são de minha autoria.

2 Mailer (1998, p. 25). As demais citações referem-se a essa edição. O título será abreviado ESF e será incluído entre parênteses no texto, seguido do número da página citada.

${ }^{3}$ Vidal (1993, p. 114). As demais citações referem-se a essa edição. O título será abreviado AVDC e será incluído entre parênteses no texto, seguido do número da página citada.

${ }^{4}$ Paulo reitera esse ponto em várias epístolas. Em 1 Cor $(15,17)$ ele afirma: "E se Cristo não ressucitou, é inútil a vossa fé, e ainda estais em vossos pecados.".

Abstract

In The gospel according to the Son, Norman Mailer rewrites the gospel story from Jesus' point of view, and in Live from Golgotha, Gore Vidal weaves a subversive and blasphemous version of Jesus' life while rewriting the Acts of the Apostles. Both narratives contribute to a questioning of Christian premises.

Key words: Rewriting. Jesus' story. Revisionism. Subversion.

\section{Referências}

BLEHL, Vincent F. Literature and religious belief. In: Mansions of the spirit: essays in literature and religion. George A. Panichas (Ed.). New York: Hawthorn Books, 1967. p. 111-115.

CARLIN, John. "Mailer's Christ falls prey to rage and lust". Independent on Sunday, London, 27 Apr. 1997. Disponível em:<http://www.elibrary.com>. Acesso em: 1 dez. 2001.

MAILER, Norman. O Evangelho segundo o Filho. Tradução de Marcos A. Reis e Valéria Rodrigues. Rio de Janeiro: Record, 1998.

MILES, Jack. Cristo: uma crise na vida de Deus. Tradução de Carlos Eduardo Lins da Silva e Maria Cecília de Sá Porto. São Paulo: Companhia das Letras, 2002.

MORARU, Christian. Rewriting: postmodern narrative and cultural critique in the age of cloning. Albany: State of New York Press, 2001.

NIETZSCHE, Friedrich. O anticristo. Tradução de Pietro Nasseti. São Paulo: Martin Claret, 2002.

PERRONE-MOISÉS, Leyla. O Evangelho segundo Saramago. In: BERRINI, Beatriz (Org.). José Saramago: uma homenagem. São Paulo: EDUC, 1999. p. 239-258.

PRICE, Robert. Deconstructing Jesus. New York: Prometheus Books, 2000. 
SOUSA, Mauro A. Introdução. In: NIETZSCHE, Friedrich. $O$ anticristo. Tradução de Pietro Nasseti. São Paulo: Martin Claret, 2002. p. $20-35$.

STRAUSS, David. The life of Jesus critically examined. Translated by George Eliot. Ramsey, NJ: Sigler Press, 1994.

VIDAL, Gore. Ao vivo do Calvário. Trad. Lia Wyler. Rio de Janeiro: Rocco, 1993. 